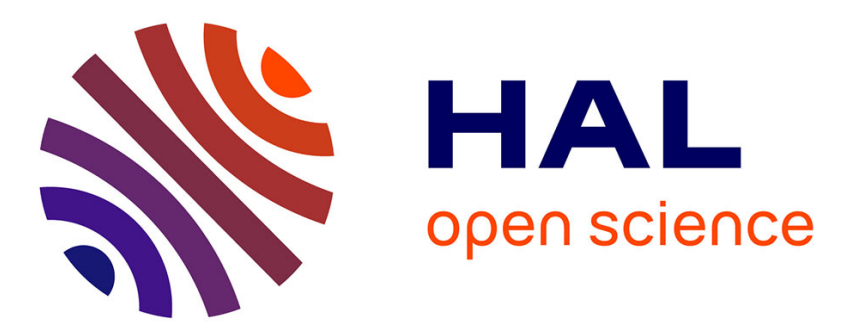

\title{
Pharmaceutical powders compaction: Experimental and numerical analysis of the density distribution
}

\author{
Moulay S. Kadiri, Abderrahim Michrafy, John A. Dodds
}

\section{To cite this version:}

Moulay S. Kadiri, Abderrahim Michrafy, John A. Dodds. Pharmaceutical powders compaction: Experimental and numerical analysis of the density distribution. Powder Technology, 2005, 157 (1-3), pp.176-182. 10.1016/j.powtec.2005.05.025 . hal-01829580

\section{HAL Id: hal-01829580 \\ https://imt-mines-albi.hal.science/hal-01829580}

Submitted on 6 Sep 2018

HAL is a multi-disciplinary open access archive for the deposit and dissemination of scientific research documents, whether they are published or not. The documents may come from teaching and research institutions in France or abroad, or from public or private research centers.
L'archive ouverte pluridisciplinaire HAL, est destinée au dépôt et à la diffusion de documents scientifiques de niveau recherche, publiés ou non, émanant des établissements d'enseignement et de recherche français ou étrangers, des laboratoires publics ou privés. 


\title{
Pharmaceutical powders compaction: Experimental and numerical analysis of the density distribution
}

\author{
M.S. Kadiri, A. Michrafy *, J.A. Dodds \\ Chemical Engineering Laboratory for Particulate solids, UMR 2392, Ecole des Mines d'Albi-Carmaux, France
}

\begin{abstract}
This paper investigates the axial density distribution during the single action compaction of pharmaceutical powders in rigid dies. Experimental results of the compaction of microcrystalline cellulose are compared to those predicted with an analytical model and with numerical analysis. The axial density distribution within tablets compacted at different loads are measured using a mercury porosimeter of slices from tablets. The analytical model based on the Janssen-Walker analysis coupled with the Heckel equation is applied to determine the axial density distribution. Representing the mechanical behaviour of the powder compaction with the Drucker-Prager/Cap model and by measuring the die wall friction, computation of the axial density within the tablet is also obtained by solving the boundary problem with finite element method for the loading-unloading cycle.

Results of the axial density obtained with the analytical model and numerical method at end of the loading step show a qualitative agreement with the measured data. However, the measurements are better predicted with the numerical results obtained with the simulation of the loading-unloading phases.
\end{abstract}

Keywords: Compaction; Density distribution; Finite element modelling; Analytical modelling

\section{Introduction}

Compaction is an important industrial manufacturing process of agglomeration of particulate solids on size enlargement with suitable properties for handling, for storage or for further processing. This technology is used for various solid materials such as metallic (PM), pharmaceutical or food powders.

While the net shape size, complicate geometry and near full density concern the compaction process of PM, the pharmaceutical powders are concerned by the particle size (fine or ultrafine) and simple geometry (flat, embossed or oval). Moreover, the relative density for pharmaceutical powder varies from low values, generally between 0.2 and 0.4 and higher values typically between 0.8 and 0.9 .

\footnotetext{
* Corresponding author. Tel.: +33 563493162.

E-mail address: michrafy@enstimac.fr (A. Michrafy).
}

However, the knowledge of the relative density distribution within the compact is of common interest of the compaction of all particle solids and its prediction is not often easy.

Continuum mechanical modelling of the compaction with finite element method (FEM) has been largely investigated for the compaction of PM [1-3], but only recently adapted to pharmaceutical powders $[4,5]$.

In order to develop numerical tools predicting the density distribution within a tablet, experiments need to be conducted to determine the mechanical properties of the powder during the compaction. Moreover to be credible, the numerical prediction has to be compared to the experimental measurements of the density distribution. Different procedures are used to measure the density distribution within tablet such as microindentation [6,7], X-ray tomography [8], NMR radioscopy (Nuclear Magnetic Resonance) [9] and auto-radiograph [10]. Recently in [11] a simple procedure was used to investigate the axial density distribution in 
Table 1

Properties of the powder used

\begin{tabular}{llll}
\hline Powder & $\begin{array}{l}\text { Mean particle } \\
\text { size }\end{array}$ & True density & Bulk density \\
\hline $\begin{array}{l}\text { MCC } \\
\text { Vivapur 102 }\end{array}$ & $90 \mu \mathrm{m}$ & $1.59 \pm 0.002 \mathrm{~g} / \mathrm{cm}^{3}$ & $0.31 \pm 0.02 \mathrm{~g} / \mathrm{cm}^{3}$ \\
\hline
\end{tabular}

tablet of microcrystalline cellulose. Results of these techniques are often qualitative [12].

In general, measurements of the density distribution are conducted on tablet after its ejection from the die. However, the predicted values with FEM are evaluated from the simulation at the end of compaction. Comparison between the measured and the calculated density seems to give good correlation for PM because the initial density of the green is typically 0.6 and the behaviour of metallic powder further this density is essentially by plastic deformation. The elastic recovery during the unloading step has negligible effect on the changes of the density distribution. This is not the case for pharmaceutical powders where at the unloading phase, the expansion of tablet is non-negligible and often the capping phenomenon happens. Comparison between experiments and numerical results has to take into account changes during the unloading step.

In the present work, experiments analytical modelling and numerical simulation with finite element method have been conducted. The main focus of this investigation is to predict the axial density distribution within a cylindrical tablet compacted at different loads. The analytical model is based on the Janssen-Walker analysis coupled with the Heckel equation. It is seen as an extension of the Heckel equation. In this modelling, the relative density of a slice at the height $h$ from the top is expressed explicitly as a function of the transmission ratio, the aspect ratio and the two classical constants of Heckel equation.

In the continuum modelling, the powder compaction behaviour is represented as elastic-plastic porous material. The yield function is described by the Drucker-Prager/Cap

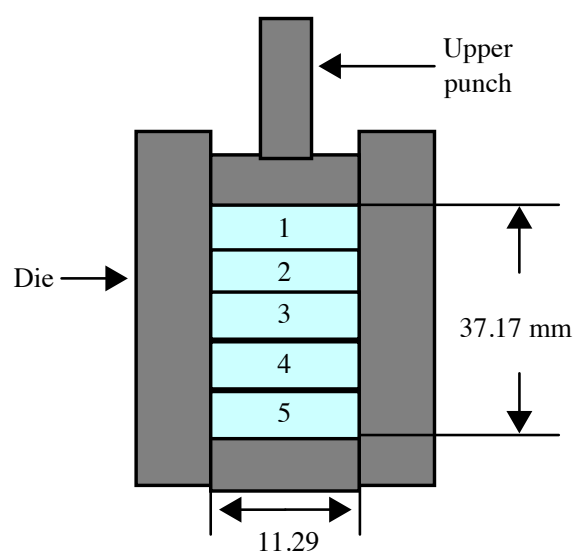

Fig. 1. Compaction in unlubricated die of five slices pre-compacted up to $10 \mathrm{MPa}$.

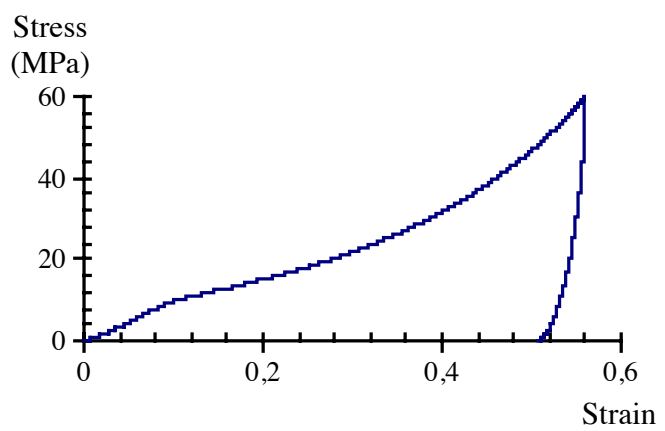

Fig. 2. Compaction curve of the five slices up to $60 \mathrm{MPa}$.

model [13]. Macroscopic characteristics of the powder such as cohesion, internal friction angle and elastic properties (Young's modulus and Poisson ratio) are fitted from experimental data. As the friction between powder and dies plays an important role for the compaction process, the Coulomb friction coefficient is estimated with an instrumented press [11].

\section{Experimental procedure}

The microcrystalline cellulose Vivapur 102 (MCC 102) is often used as a pharmaceutical excipient. Characteristics of the powder MCC 102 provided by JRS (J. Rettenmaier and Söhne) is shown in Table 1. To measure the axial density along the height of the compact, it was difficult to cut a tablet in several slices without damage. This procedure is often used for metallic powders compaction. To circumvent this difficulty, we proceeded in the following way. Thin and similar tablets of the same mass $0.55 \mathrm{~g}$ of MCC 102 were compacted with an instrumented press up to $10 \mathrm{MPa}$ in a cylindrical die lubricated with magnesium stearate. The die diameter was $11.28 \mathrm{~mm}$. This level of load gives a certain cohesion to thin tablets. Moreover, the dies lubrication allows a certain homogeneity of the density. Once ejected and because of the elastic recovery mechanisms, the diameter of thin tablets is slightly lower than $11.29 \mathrm{~mm}$. The following steps consist to pile up these compacts by group of five thin tablets in a non-lubricated die of diameter $11.29 \mathrm{~mm}$ (Fig. 1). Each group of five slices is compressed with a maximum load of

Table 2

Case $60 \mathrm{MPa}$ : relative densities of the slices after ejection

\begin{tabular}{llllll}
\hline$h(\mathrm{~mm})^{\mathrm{a}}$ & Test 1 & Test 2 & Test 3 & Mean & Standard dev. \\
\hline 21.37 & 0.7315 & 0.7446 & 0.7312 & 0.7358 & 0.00625403 \\
16.74 & 0.7242 & 0.7302 & 0.7272 & 0.7271 & 0.00245332 \\
12.02 & 0.7194 & 0.7113 & 0.7176 & 0.7162 & 0.00346503 \\
7.245 & 0.7107 & 0.7082 & 0.7097 & 0.7096 & 0.00102694 \\
2.422 & 0.7037 & 0.7006 & 0.7032 & 0.7025 & 0.00133682 \\
\hline
\end{tabular}

${ }^{\text {a }} h$ is the distance from the bottom of the compact (origin) to the slice center (see Fig. 3). 


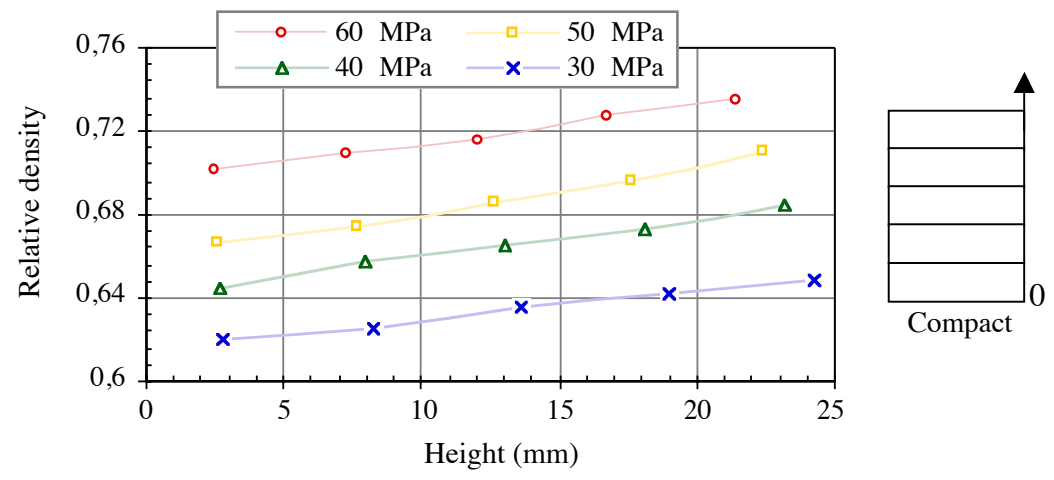

Fig. 3. Evolution of the relative density according to the height $h$ ( $h$ is the distance from the bottom to the slice center).

30, 40, 50 or $60 \mathrm{MPa}$. The compact formed is then ejected and the slices are separated. No damage was noted on the surface contact between slices. After the expansion of the slices, their densities were measured with the mercury porosimeter.

The average initial relative density of the five piled slices was $0.46( \pm 0.002)$. In Fig. 2 the compaction curve of the five slices compacted up to $60 \mathrm{MPa}$ was plotted. To be ensured of the reproducibility of results, the test was repeated thrice. The density was measured with the mercury porosimeter of slices after ejection and separation and the true density of the powder. Results of the case of the compaction up to $60 \mathrm{MPa}$ were presented in Table 2 . In Fig. 3 the relative density versus the height for the applied loads was plotted. Results show that the relative density decreases from the top to the bottom of the compact. It can be noted that the maximum and the minimum densities for each tablet increase with the applied stress. These conclusions are consistent with those in the literature [14]. Similar tendencies of the distribution were also obtained by coloured layer method for $6 \mathrm{~g}$ of alumina compacted up to $70 \mathrm{MPa}$ [15].

\section{Analytical density-axial stress relationship}

The most commonly relationship between the applied pressure and the density within a pharmaceutical tablet is the empirical Heckel equation:

$\ln \left(1 /\left(1-\rho_{\mathrm{r}}\right)\right)=A+K \sigma_{\text {upp }}$

where $\rho_{\mathrm{r}}$ is the relative density of the compact, $A$ and $K$ are constants which may be determined from experimental data. Eq. (1) does not taken into account the gradient density generated by the die-wall friction and friction between particles. To introduce the effect of the stress distribution along the tablet height, the Janssen-Walker approximation based on the "method of differential slices" was used [16]. In this analysis, the axial stress applied on a slice situated at a depth $h$ (Fig. 4) is expressed as:

$\sigma_{\mathrm{h}}=\sigma_{\text {upp }} \exp (-4 \mu \alpha h / D)$ where $\sigma_{\text {upp }}=F_{\text {upp }} /\left(\pi D^{2} / 4\right)$ is the mean axial stress transmitted by the upper punch to the tablet and $D$ the diameter of the die. The constant $\alpha$ may be related to the Janssen constant and the Walker distribution factor [16] and may be interpreted as the ratio of the radial to mean axial stress $\left(\alpha=\sigma_{\mathrm{rr}} / \sigma_{\mathrm{h}}\right)$. The coefficient $\mu$ is the Coulombian friction coefficient between the powder and the die.

Combining Eqs. (1) and (2), it results:

$\ln \left(1 /\left(1-\rho_{\mathrm{r}}(h)\right)=A+K \sigma_{\text {upp }} \exp (-4 \mu \alpha h / D)\right.$.

However, using Eq. (2) for a given applied stress $\sigma_{\text {upp }}$ the tablet height $H$ is known and the friction coefficient $\mu(H)$ may be expressed as:

$\mu=\ln \left(\sigma_{\text {low }} / \sigma_{\text {upp }}\right) /(-4 \alpha H / D)$

where $\sigma_{\text {low }}$ is the axial stress transmitted to the lower punch.

Eq. (4) was used in [11] to compare different lubrication modes in the compaction of microcrystalline cellulose powder.

Hence, from Eqs. (3) and (4), it follows :

$\ln \left(1 /\left(1-\rho_{\mathrm{r}}(h)\right)=A+K \sigma_{\text {upp }} \exp \left(\ln \left(\sigma_{\text {low }} / \sigma_{\text {upp }}\right) h / H\right)\right.$.

Eq. (5) is an extension of the Heckel equation where a certain form of the density gradient (in the sense of the

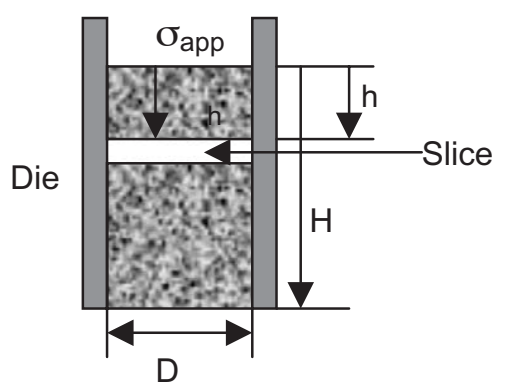

Fig. 4. Mean axial stress $\sigma_{\mathrm{h}}$ at the depth $h$ from the top of the compact, for a given applied pressure $\sigma_{\text {upp }}$. 


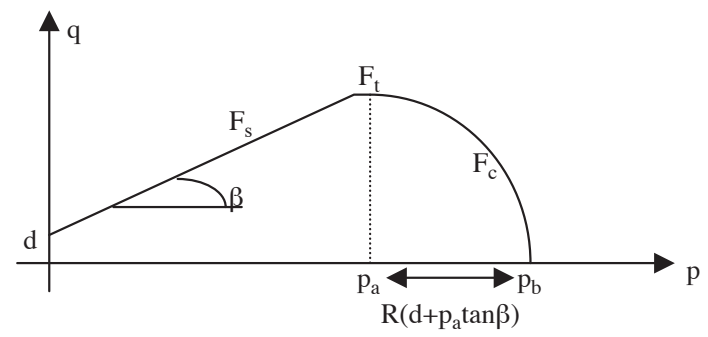

Fig. 5. The Drucker-Prager/Cap model presented in the $(p, q)$ plane.

Janssen-Walker analysis) is taken into account. The constants $A$ and $K$ are fitted as in the Heckel equation and were 0.56 and $0.016 \mathrm{MPa}^{-1}$ for $\sigma_{\text {upp }}=60 \mathrm{MPa}$.

\section{Continuum mechanical modelling}

In continuum mechanical modelling, the powder is considered macroscopically as continuous and porous medium. The media is characterised by overall parameters such as cohesion, interparticle friction and mechanical properties such as Young's modulus and Poisson ratio which are depending on density during the compaction. In addition, as the applied load increases, the admissible stress in the tablet must be bounded in a domain which is bounded by one or a set of surfaces in the pressure and deviatoric space. This domain defines the yield surface. However, to describe mechanisms such as hardening and softening resulting from the loading and unloading of the powder, the domain expands or contracts as the volumetric strain decreases or increases. This evolution is defined a flow function or flow potential.

\subsection{Yield function}

Several continuum models have been developed for the powder compaction. They are based on the formalism of the elastic-plastic theory and with different yield and flow functions. One of these models is the Drucker-Prager/Cap model [13] implemented in the Abaqus Software. The yield

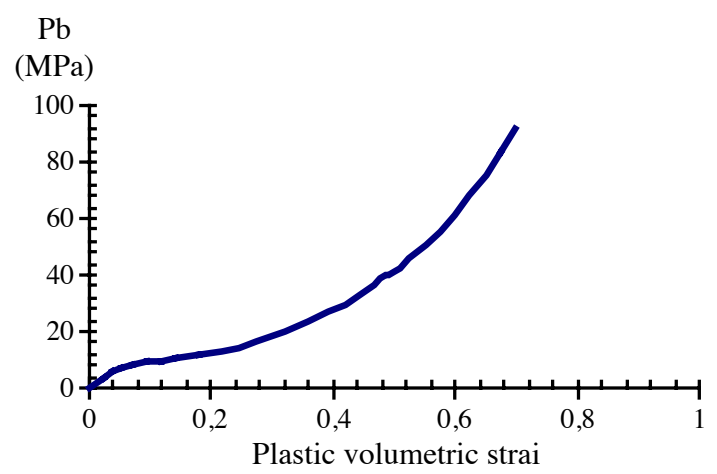

Fig. 6. Hardening function $P_{\mathrm{b}}$.

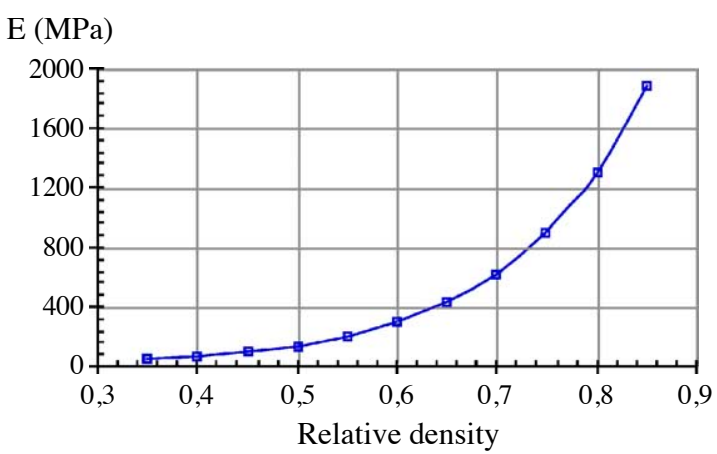

Fig. 7. Young's modulus $E$ versus relative density (MCC Vivapur 102).

function is defined with tree surfaces represented in Fig. 5: the shear failure surface $F_{\mathrm{s}}$ defining the correlation between the cohesion $d$ and the internal friction angle $\beta$, the elliptical surface (or Cap surface) $F_{\mathrm{c}}$ which can expand or contract according to the volumetric strain and the transition surface $F_{\mathrm{t}}$ between $F_{\mathrm{s}}$ and $F_{\mathrm{c}}$. The evolution of the Cap surface is described with the hardening function $P_{\mathrm{b}}$ which is the position of the Cap on hydrostatic pressure axis for each density state.

Application of the Drucker-Prager/cap model to the compaction of pharmaceutical powders and the procedure to fit parameters can found in [4]. Other calibration procedure can found in [13].

\subsection{Parameters model determination}

From the experimental data of the compaction cycle (Fig. 2 ), the hardening function was calculated and plotted versus the volumetric strain in Fig. 6. The resulting initial cohesion and internal friction angle were typically $0.54 \mathrm{MPa}$ and $40.9^{\circ}$. The Young modulus $E$ was estimated from the simple compression test. Values are increasing with the relative density as it is plotted in Fig. 7. In contrast, results of the Poisson ratio found are decreasing in the range $0.4-0.8$ of the relative density and increasing between 0.8 and 0.95 of the relative density. Such behaviour was presented in [17] and [18]. However, in [5], the Poisson ratio of MCC 102 was found as monotonic increasing function with the

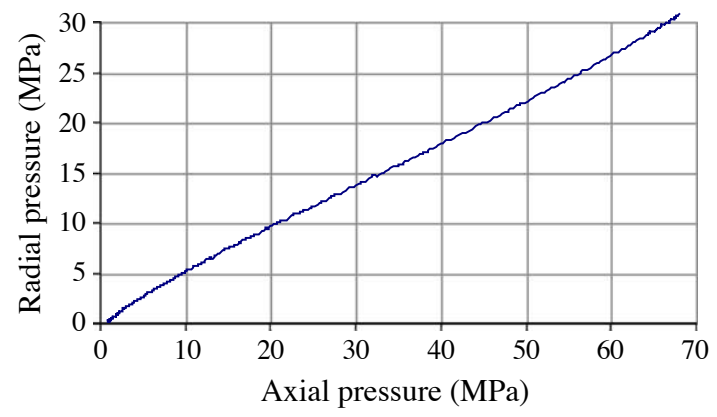

Fig. 8. Radial pressure versus axial pressure during compaction of the powder MCC 102 in an unlubricated die. 


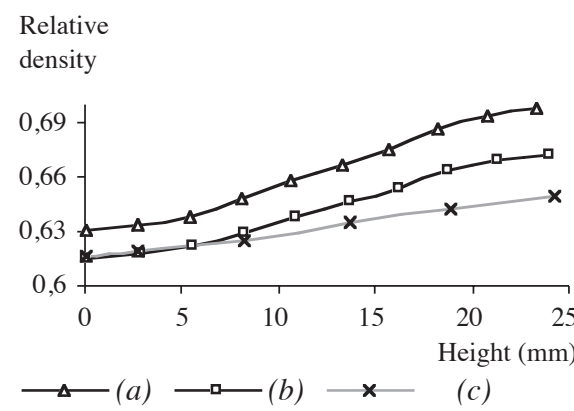

Applied pressure $30 \mathrm{MPa}$

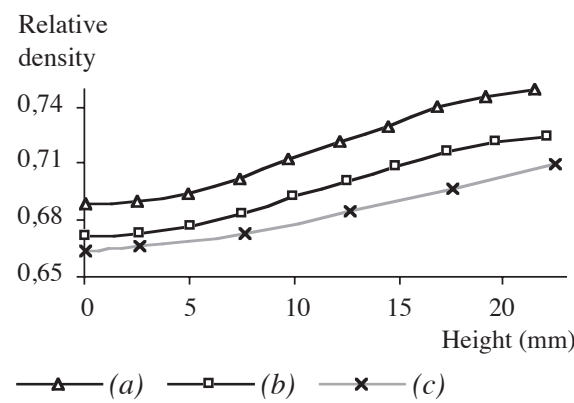

Applied pressure $50 \mathrm{MPa}$

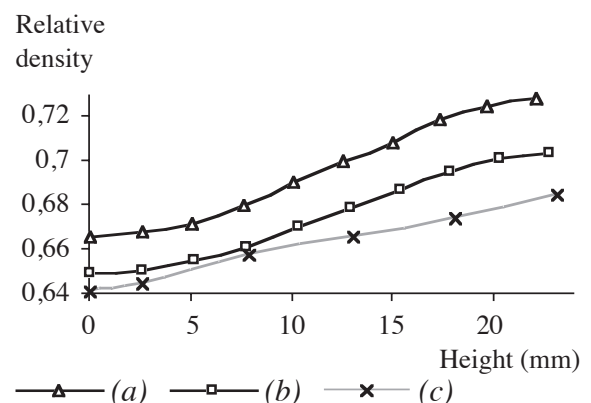

Applied pressure $40 \mathrm{MPa}$

Relative

density

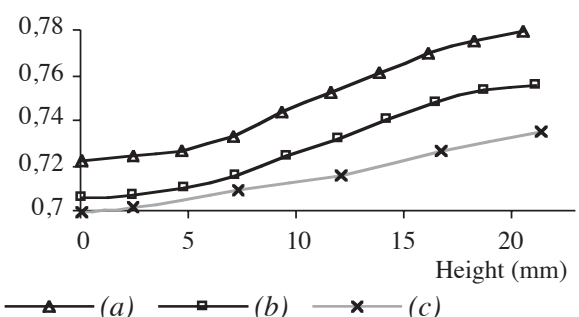

Applied pressure $60 \mathrm{MPa}$

Fig. 9. Axial relative density distribution for the applied pressure 30, 40, 50 and $60 \mathrm{MPa}$. (a) Simulation at the end of compaction (loading step). (b) Simulation after unloading step. (c) Experiment.

relative density in the range $0.3-1$. To avoid any bad interpretation of the Poisson ratio without testing others' techniques, for comparison, the average value of the Poisson ratio, typically 0.18 , was assumed for the simulation of the compaction.

To complete the boundary problem of the compaction, the die wall friction coefficient is needed. It was estimated from Eq. (4). In the case of the compaction up to $60 \mathrm{MPa}$, the transmission ratio $\sigma_{\text {low }} / \sigma_{\text {upp }}$ was $65 \%$ and the aspect ratio $H / D$ was 2.01. The compaction of the MCC powder without lubrication in an instrumented die with a radial gauge was used to characterise the transfer ratio $\alpha$. The resulting radial stress versus the axial stress is plotted in Fig. 8. The radial stress increases linearly with the axial stress. The slope of the curve that is typically 0.45 was assumed to represent the transfer ratio $\alpha$. The resulting friction coefficient is then equal to 0.12 .

\subsection{Simulation of the compaction and results}

To solve the quasi-static boundary problem of the compaction, the Abaqus/Standard Software was used. The classical implicit discretization of the loading time was applied. The loading and the unloading steps were simulated

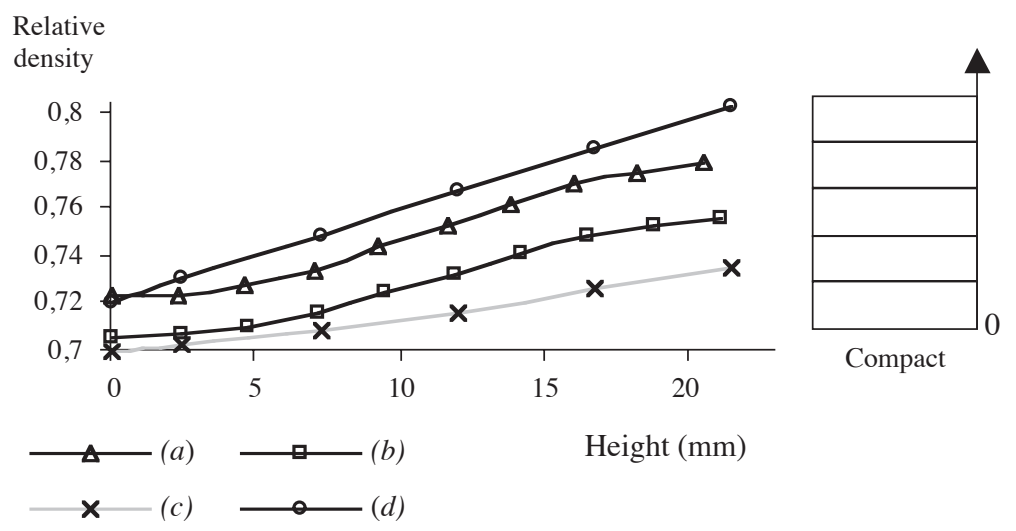

Fig. 10. Relative density evolution along the compact height. (a) Results at the end of compaction $\left(\sigma_{\text {upp }}=60 \mathrm{MPa}\right.$ ). (b) Results after unloading. (c) Experimental measurements. (d) Results from the analytical model. 
for the compaction of axisymmetric bed of powder. Initial dimension of the powder bed was the same as in the experiment and the initial relative density $\rho_{\mathrm{r}, \mathrm{i}}$ of the powder bed was 0.46 . The half of the powder bed (axial symmetry reason) was meshed using four-node axisymmetric continuum elements (CAX4).

Stress and strain distributions in the tablet are computed during the loading and unloading steps. The relative density was evaluated on each finite element from its volume change. The correlation between the density and the strain is initially presented by Kuhn and Downey [19] and takes the following expression:

$\rho_{\mathrm{r}}=\rho_{\mathrm{r}, \mathrm{i}} \exp \left(-\varepsilon_{\mathrm{vol}}\right)$

where $\varepsilon_{\mathrm{vol}}$ is the volumetric strain in the finite element.

It is thus possible from Eq. (6) to compute the density distribution within the tablet at each time loading. In our purpose, only the focus of the axial density distribution will be presented.

Fig. 9a-d show axial relative density distribution obtained with finite element calculation and with experiment for the applied loads 30, 40, 50 and $60 \mathrm{MPa}$. To show the difference between the density distribution at end of the compaction (loading step) and after the unloading, the two calculated distributions are plotted. It can be seen that the axial density distribution within the tablet obtained by the simulation of the unloading presents better approximation of the measurements.

Fig. 10 shows results of the analytical, numerical and experiment of the axial relative density for the compaction up to $60 \mathrm{MPa}$. Predictions with the analytical approach and the simulation of the loading present a qualitative agreement with the measured values. Similar predictions were published in [15] for the compaction of the alumina powder. However, taking into account the unloading in the simulation, the obtained results are better comparatively to the measurements. However, it can be mentioned here that the simulation of the ejection may render the results more better again because the relaxation continues. This simulation was tested, but due to some divergence problems, results are not presented here.

\section{Conclusion}

Axial density distribution during the compaction of microcrystalline cellulose powder in rigid dies was investigated with analytical and numerical computations and experiments. The analytical model is expressed from the Janssen-Walker analysis coupled with the Heckel equation. The numerical analysis is based on the elasticplastic theory and the Drucker-Prager/Cap yield function. The axial density was measured using a mercury porosimeter to slices from tablets. The die wall friction coefficient was estimated from experiment. The resulting boundary problem of the compaction was solved with finite element method for a compaction cycle: loading and unloading.

The axial density obtained with the analytical model, the numerical method and the measurement decreases from the top to the bottom of the compact. The numerical results obtained with the simulation of the unloading phase are in a qualitative agreement with the measured data. The experimental procedure tested is an interesting tool to compare the simulation and the measurement.

$\begin{array}{ll}\text { List of symbols } \\ \rho_{\mathrm{r}}, \rho_{\mathrm{r}, \mathrm{i}} & \text { relative density, initial relative density } \\ A, K & \text { Heckel constants } \\ \sigma_{\mathrm{h}} & \text { mean stress at the depth } h \text { from the top of tablet } \\ \sigma_{\mathrm{upp}} & \begin{array}{l}\text { axial stress on the upper punch } \\ \sigma_{\text {low }}\end{array} \\ \mu & \begin{array}{l}\text { axial stress transmitted to the lower punch } \\ \text { friction coefficient }\end{array} \\ D & \text { diameter of the die } \\ H & \text { tablet thickness } \\ \alpha & \text { transfer coefficient (ratio of radial to axial stress) } \\ d, \beta & \text { cohesion and friction angle of powder, respectively } \\ E & \text { Young's modulus } \\ P_{\mathrm{b}} & \text { Hardening function } \\ F_{\mathrm{s}} & \text { shear failure yield surface } \\ F_{\mathrm{c}} & \text { cap yield surface } \\ F_{\mathrm{t}} & \text { transition yield surface } \\ \varepsilon_{\mathrm{vol}} & \text { volumetric plastic strain }\end{array}$

\section{References}

[1] F. Toussaint, Etude expérimentale et simulation numérique de la mise en forme par compression et frittage de poudres, Thèse de doctorat à l'INPG, 2001.

[2] J. Cedergren, N.J. Sorensen, A. Bergmark, Three-dimensional analysis of compaction of metal powder, Mech. Mater. 34 (2002) 43-59.

[3] H. Park, K.T. Kim, Consolidation behavior of $\mathrm{SiC}$ powder under cold compaction, Mater. Sci. Eng. A 299 (2001) 116-124.

[4] A. Michrafy, D. Ringenbacher, P. Tchoreloff, Modelling the compaction behaviour of powders: application to pharmaceutical powders, Powder Technol. 127 (2002) , 257-266.

[5] I.C. Sinka, J.C. Cunningham, A. Zavaliangos, The effect of wall friction in the compaction of pharmaceutical tablets with curved faces: a validation study of the Drucker-Prager Cap model, Powder Technol. 133 (2003) 33-43.

[6] H.N. Han, H.S. Kim, K.H. Oh, D.N. Lee, Elastoplastic finite element analysis for porous metals, Powder Metall. 37 (2) (1994) $140-146$.

[7] K.T. Kim, S.W. Choi, H. Park, Densification behaviour of ceramic powder under cold compaction, J. Eng. Mater. Technol. 122 (2000 April) 238-244.

[8] L. Farber, G. Tardos, J.N. Michaels, Use of X-ray tomography to study thr porosity and morphology of granules, Powder Technol. 132 (2003) $57-63$.

[9] G. Nebgen, D. Gross, V. Lehmann, F. Muller, ${ }^{1} \mathrm{H}-\mathrm{NMR}$ microscopy of tablets, J. Pharm. Sci. 84 (1977) 283-291.

[10] I. Aydin, B.J. Briscoe, K.Y. Sanlitürk, The internal form of compacted ceramic components: a comparison of finite element modelling with experiment, Powder Technol. 89 (1996) 239-254. 
[11] A. Michrafy, M.S. Kadiri, J.A. Dodds, Wall friction and its effects on the density distribution in the compaction of pharmaceutical excipients, Trans. Inst. Chem. Eng. 81 (Part A) (2003) 946-952.

[12] T. Thomas, Contribution à la compréhension des phénomènes physiques et métallurgiques intervenant durant la consolidation dynamique de poudres, Thèse de doctorat, 1992, ENSMP.

[13] Hibbit, Karlsson, and Sorensson, Inc. ABAQUS Theory Manual Version 5.8, p. 4.4.4-1.

[14] R. Kamm, M.A. Steinberg, J. Wulff, Trans. Am. Inst. Min. Metall. Pet. Eng. 171 (1947) 439.

[15] B.J. Briscoe, S.L. Rough, The effects of the wall friction in powder compaction, Colloids Surf., A Physicochem. Eng. Asp. 137 (1998) $103-116$.
[16] R.M. Nedderman, Statics and Kinematics of Granular Materials, Cambridge University Press, 1992.

[17] I.M. Al-Khattat, S.T.S. Al-Hassani, Towards a computer-aided analysis and design of tablet compaction, Chem. Eng. Sci. 42 (4) (1987) 707-712.

[18] J. Ketolainen, et al., Photoacoustic evaluation of elasticity and integrity of pharmaceutical tablets, Int. J. Pharm. 125 (1995) 45-53.

[19] H.A. Kuhn, C.L. Downey, Deformation characteristics and plasticity theory of sintered powder materials, Int. J. Powder Metall. 7 (1971) 15-25. 